\title{
An immunohistochemical study of e-cadherin expression in primary oral squamous cell carcinoma and metastatic lymph node in a tertiary care centre
}

\author{
Talukdar L. ${ }^{1}$, Goswami A. ${ }^{2}$ \\ ${ }^{1}$ Dr. Leena Talukdar, Associate Professor, Department of Pathology, Gauhati Medical College \& Hospital, Guwahati, Assam, \\ India, ${ }^{2}$ Dr. Anirban Goswami, Consultant Pathologist, Life Care Diagnostic, Maligaon, Guwahati, Assam, India
}

Corresponding Author: Dr. Anirban Goswami, Consultant Pathologist, Life Care Diagnostic, Maligaon, Guwahati, Assam, India. E-mail: anirbangoswami1234@gmail.com

\begin{abstract}
Background: Cancers arising from the oral cavity are mostly squamous cell carcinomas. E-cadherin is encoded by the CDH1 gene, helps in maintaining cell polarity and normal tissue architecture. loss of epithelial E-cadherin expression increases tumor invasiveness and metastasis. In the present study, the expression of epithelial E-cadherin in oral squamous cell carcinoma along with its grading is evaluated with immunohistochemical examination. Material and Method: Oral biopsy specimens received were fixed in 10\% formaldehyde solution. Histological diagnosis was made on haematoxylin and eosin stained sections and expression of E cadherin is assessed by Immunohistochemistry. Results: In the present study out of 86 cases of OSCC, 57 were male and 29 were female with a M:F 1.9: 1. E-cadherin immunohistochemistry showed 4+ degree of expression in 15/51 (29\%) cases in well differentiated carcinoma while in poorly differentiated carcinoma $4+$ expression was showed only by $1 / 14$ case. Differences in the expression of epithelial E-cadherin were statistically significant $(p<0.001)$ between all the histopathological grades. Any statistically significant association between the expressions of E-cadherin and clinicopathological variables such as age, sex, site and lymph node metastasis in OSCCs was not observed. Also, this study found no statistically significant association between OSCC with and without lymph node metastases and clinical variables like age, sex, site, and histological differentiation. Conclusion: Further research on E-cadherin and other related biomolecules can help us in early diagnosis and treatment of oral squamous cell carcinoma.
\end{abstract}

Keywords: Squamous cell carcinomas, E-cadherin, Immunohistochemistry

\section{Introduction}

Cancers arising from the oral cavity are mostly squamous cell carcinomas [1]. It commonly affects people over 40 years of age with male predominance. Tongue, soft palate, lower lip, floor of the mouth and the gingivo-buccal sulcus are the commonest site for occurrence of oral squamous cell carcinoma [2]. Tobacco and alcohol consumption are the most significant risk factors for oral squamous cell carcinoma (OSCC) [3]. Although, the diagnosis and treatment has improved a lot, still the 5-year survival rate in OSCC is only about $50 \%$, which is due to a large number of patients presents with advanced disease stage and regional lymph node metastasis $[4,5,6]$. So, for the development of anticancer therapeutics, it is very imperative to know the basic mechanism of metastatic dissemination of oral squamous cell carcinoma. E-cadherin is encoded by the $\mathrm{CDH} 1$ gene located on chromosome 16q21. It is a calciumdependent transmembrane glycoprotein which is expressed

Manuscript received: $4^{\text {th }}$ October 2019

Reviewed: $14^{\text {th }}$ October 2019

Author Corrected: $20^{\text {th }}$ October 2019

Accepted for Publication: $23^{\text {rd }}$ October 2019 in most epithelial cells and helps in maintaining cell polarity and normal tissue architecture [7]. The intracellular domain of E-cadherin is linked to the actin cytoskeleton through the catenins ( $\alpha, \beta$, and $\gamma$-catenin) [8]. Various study established that, with loss of epithelial E-cadherin expression, there is decrease in tumor differentiation and increased chances of metastatic dissemination, suggesting the role of E-cadherin in tumor invasiveness and metastasis $[9,10]$ Few other studies showed that E-cadherin expression is strongly associated with overall survival [11]. In the present study, the expression of epithelial E-cadherin in oral squamous cell carcinoma along with its grading is evaluated with histopathological and immunohistochemical examination.

\section{Material and Methods}

Study period: The present study includes 86 cases of primary OSCC diagnosed histopathologically from March 2017 to February 2018 (1 year) in the Department of Pathology, Silchar Medical College. Another 14 cases

Pathology Update: Tropical Journal of Pathology \& Microbiology Available online at: www.medresearch.in 884 | P a g e 
included as control group with a clinical suspicion of malignancy but diagnosed as normal to inflammatory lesions on histology. Out of 86 cases of OSCC, 41 cases show regional lymph node metastasis confirmed by histological examination. Immunohistochemistry (IHC) with E cadherin was performed in all 86 cases of OSCC and 14 cases showing normal to inflammatory lesion.

Histopathological evaluation: Oral biopsy specimens received were fixed in $10 \%$ formaldehyde solution. The specimens were then sectioned from representative areas. Histological diagnosis was made on haematoxylin and eosin stained sections. The selected paraffin embedded tissue blocks, after section cutting were taken up on polylysine coated slides for IHC procedure.

Immunohistochemistry procedure: Antibody to Ecadherin (EP700Y) (Rabbit Monoclonal Primary Antibody, prediluted, Cell Marque) was used as primary antibody, sections of infiltrating duct carcinoma of the breast were used as the positive controls. Tissue sections without incubation of primary antibody were used as negative controls. Slides were put at $60^{\circ}$ Celsius in hot air oven for 60 minutes and then put in xylene for 2 changes for 10 minutes each for De-paraffinisation. Slides were passed through decreasing grades of alcohol and running water for 5 minutes each. Antigen retrieval was done using Tris EDTA based antigen retrieval solution with a $\mathrm{pH}$ of 9. The microwave method of antigen retrieval is done in our IHC set up which is also known as Heat Induced Epitope Retrieval (HIER) method. Slides were washed with wash buffer of $\mathrm{pH} 7.2$ to 7.6 three times 1 minute each following which Perox free blocking reagent is added to the sections and waited for 10 minutes. The slides are kept in humid chamber. Primary antibody is added to the respective slides and incubated for 60 minutes in humid chamber at room temperature. Slides were washed with wash buffer and Hi. Def Amplifier is added in tissue section and incubated for 30 minutes. Slides were again washed with wash buffer and
Polymer Hi Def HRP Label is added to the sections and incubated for 30 minutes inside the humid chamber at room temperature. After washing in wash buffer, DAB chromogen is added to the sections and waited for 10 minutes in the humidity chamber. The slides are then washed with distilled water ( 2 times) counterstained with hematoxylin. The slides are washed under running tap water for 10 minutes. The slides are then serially dehydrated in alcohol and mounted in DPX. After drying the slides, the test slides were examined along with the control sections (stained simultaneously) by light microscopy.

Evaluation of immunohistochemistry: For the evaluation of the expression of E-cadherin the proportion of positive tumor cells was visually estimated under microscope. Ecadherin was assessed using the IHC immunoreactivity score, which is a semi quantitative method based on the proportion of cells with membranous staining and the intensity of staining: Immunoreactivity score $=$ proportion positive score $\mathrm{x}$ intensity score. The proportion of positive staining was scored as - 0 if $0-20 \%$ of epithelial cells stained positive, 1 if $21-40 \%$ of cells were positive, 2 if $41-60 \%$ were positive, 3 if $61-80 \%$ were positive, or 4 if $>80 \%$ cells were positive. The intensity was scored as - 0 for negative staining, 1 for weak intensity ,2 for moderate intensity and 3 for strong intensity of staining. The total score ranges between 0 to 12 . Immunoreactivity was divided into three groups based on the final score: a total score of 0 is considered as negative immunoreactivity, score of 1-4 as low immunoreactivity and $>4$ as high immunoreactivity.

Statistical analysis: The correlation between clinicopathological parameters and E-cadherin expression were analyzed using the chi square test and Fisher's exact test. One-way ANOVA was used to compare and correlate the epithelial expression of E-cadherin in normal epithelium and different grades of squamous cell carcinoma. A p value $<0.05$ was considered statistically significant.

\section{Result}

In the present study, out of 86 cases of OSCC, 57 were male and 29 were female with a M:F 1.9: 1. Most of the cases are in between 51 to 60 years of age ( $36.05 \%$ ) (Table 1). Out of 86 cases, 51 (59.30\%) were well differentiated OSCC, $21(24.42 \%)$ were moderately differentiated and 14 (16.28\%) were poorly differentiated (Figure 1).

Table-1: Age and Sex distribution of OSCC cases

\begin{tabular}{|c|c|c|c|}
\hline Age group & Total $(\mathbf{n = 8 6})$ & Male $(\mathbf{n = 5 7})$ & Female $(\mathbf{n}=\mathbf{2 9})$ \\
\hline $21-30$ & $02(02.33 \%)$ & $01(01.75 \%)$ & $01(03.45 \%)$ \\
\hline $31-40$ & $07(08.13 \%)$ & $05(08.77 \%)$ & $02(06.90 \%)$ \\
\hline $41-50$ & $25(29.07 \%)$ & $19(33.33 \%)$ & $06(20.69 \%)$ \\
\hline $51-60$ & $31(36.05 \%)$ & $15(26.32 \%)$ & $16(55.17 \%)$ \\
\hline $61-70$ & $15(17.44 \%)$ & $12(21.06 \%)$ & $03(10.34 \%)$ \\
\hline $71-80$ & $03(03.49 \%)$ & $02(03.51 \%)$ & $01(03.45 \%)$ \\
\hline$>80$ & $03(03.49 \%)$ & $03(05.26 \%)$ & $00(00.00 \%)$ \\
\hline
\end{tabular}

Pathology Update: Tropical Journal of Pathology \& Microbiology Available online at: www.medresearch.in 885 | P a g e 


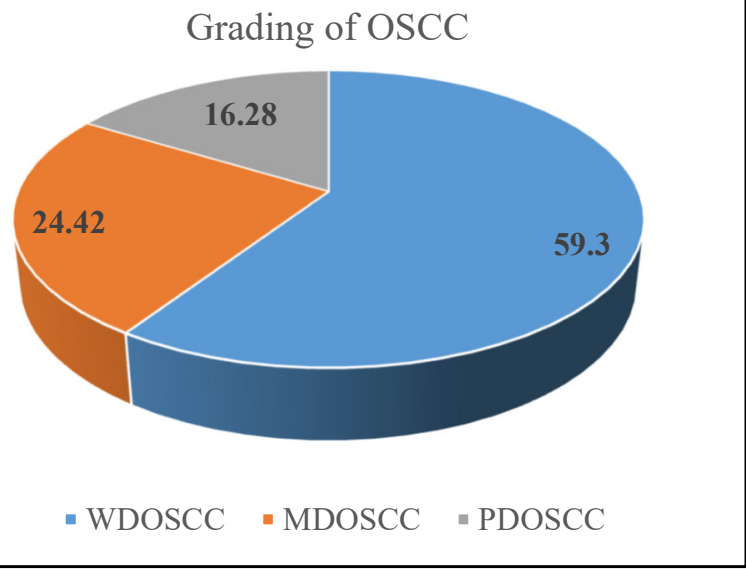

Figure 1: Distribution of different grades of $\operatorname{OSCC}(n=86)$.

Immunohistochemical evaluation E-cadherin expression: In all normal tissues, E-cadherin was localized to the epithelial cell membrane and was expressed throughout the whole thickness of the epithelium. In the present study, E-cadherin immunohistochemistry showed $4+$ degree of expression in 15/51 (29\%) cases and 3+ degree of expression in 20/51(39\%) cases in well differentiated carcinoma, while in poorly differentiated carcinoma $4+$ expression was showed only by $1 / 14$ case and only two cases showed $3+$ degree of expression (Table 2).

Table-2: Expression of E-Cadherin in different Grades of OSCC.

\begin{tabular}{|l|c|c|c|c|c|c|}
\hline Grades of OSCC & No of cases & $\mathbf{4 +}$ & $\mathbf{3 +}$ & $\mathbf{2 +}$ & $\mathbf{1 +}$ & $\mathbf{0}$ \\
\hline Well differentiated & 51 & 15 & 20 & 14 & 2 & 0 \\
\hline Moderately differentiated & 21 & 4 & 7 & 9 & 1 & 0 \\
\hline Poorly differentiated & 14 & 1 & 2 & 5 & 4 & 2 \\
\hline
\end{tabular}

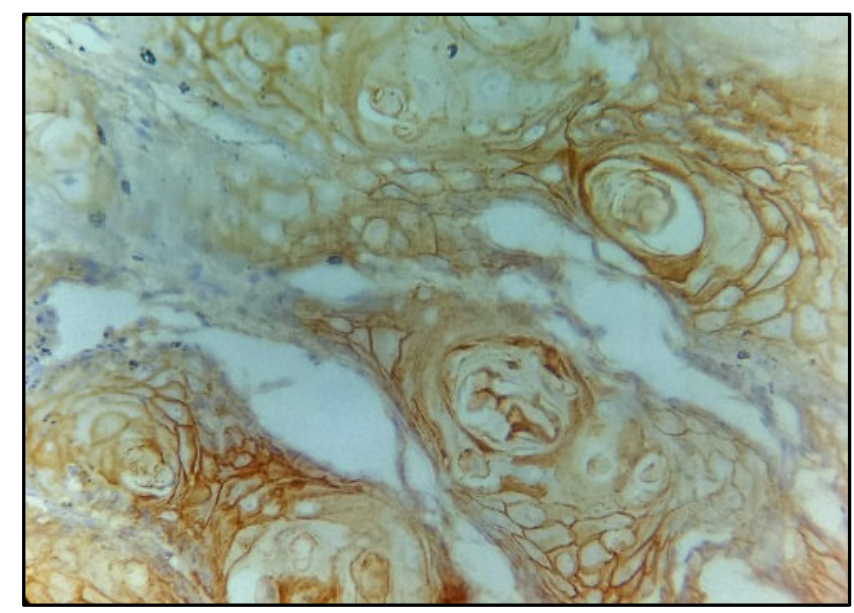

Figure 2: Expression of E-cadherin in well differentiated OSCC [40x].

Table-3: E-cadherin IHC score

\begin{tabular}{|l|c|c|c|}
\hline & Mean IHC Score & Standard deviation & P value \\
\hline Normal & 9.313 & \pm 2.024 & \multirow{2}{*}{$<0.001$} \\
\hline Well differentiated OSCC & 6.961 & \pm 2.366 & \\
\cline { 1 - 3 } Moderately differentiated OSCC & 5.524 & \pm 1.778 & \\
\cline { 1 - 3 } Poorly differentiated OSCC & 2.357 & \pm 1.336 & \\
\hline
\end{tabular}




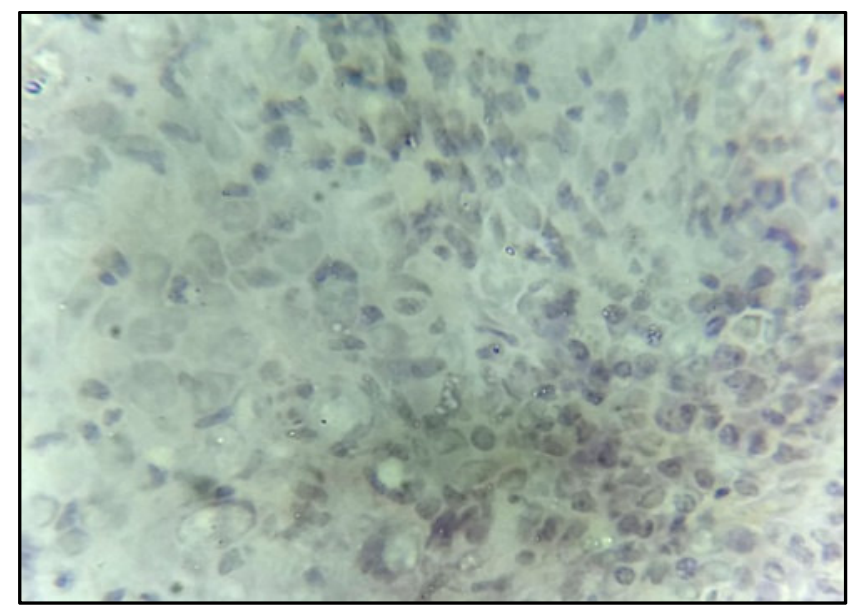

Figure 3: Expression of E-cadherin in poorly differentiated OSCC [40x].

Immunoreactivity for E-cadherin in normal epithelium was high (mean IHC score $=9.313 \pm 2.024$ ). In OSCC tissue, the expression of E-cadherin decreases from well differentiated to poorly differentiated carcinomas. In well differentiated OSCC mean IHC score was $6.961 \pm 2.366$, in moderately differentiated cases mean IHC score was $5.524 \pm 1.778$ and in poorly differentiated OSCC mean IHC score was found to be $2.357 \pm 1.336$. Differences in the expression of epithelial E-cadherin were statistically significant $(\mathrm{p}<0.001)$ between all the histopathological grades (Table 3$)$.

Table-4: Comparison of OSCC with and without lymph node metastases

\begin{tabular}{|c|c|c|c|}
\hline LN Metastasis & IHC Score $\leq \mathbf{4}$ & IHC score 5-12 & P value \\
\hline Present & 19 & 22 & 0.119 \\
\hline Absent & 13 & 32 & \\
\hline
\end{tabular}

Any significant difference in E- cadherin expression at the primary site of OSCC, with or without lymph node metastases was not observed (Table 4). Also, any statistically significant association between the expressions of E-cadherin and clinicopathological variables age, sex, site in OSCCs was not observed and hence these variables did not affect the E-cadherin expression at primary site (Table 5).

Table-5: Correlation of E-cadherin expression and clinical variables.

\begin{tabular}{|c|c|c|c|}
\hline Cinicopathological variables & IHC Score $\leq 4$ & IHC score 5-12 & P value \\
\hline \multicolumn{4}{|l|}{ 1. Sex } \\
\hline Male & 19 & 38 & \multirow[t]{2}{*}{0.349} \\
\hline Female & 13 & 16 & \\
\hline \multicolumn{4}{|l|}{ 2. Age } \\
\hline$\leq 50$ & 09 & 25 & \multirow[t]{2}{*}{0.114} \\
\hline$>50$ & 23 & 29 & \\
\hline \multicolumn{4}{|l|}{ 3. Site } \\
\hline Buccal mucosa & 11 & 29 & \multirow[t]{7}{*}{0.121} \\
\hline Dorsum of tongue & 02 & 01 & \\
\hline Floor of mouth & 01 & 03 & \\
\hline Gingivo buccal sulcus & 07 & 02 & \\
\hline Lateral border of tongue & 07 & 11 & \\
\hline Reteromolar trigone & 03 & 04 & \\
\hline Lower lip & 01 & 04 & \\
\hline
\end{tabular}


Table-6: Correlation between clinicopathological variables and lymph node status.

\begin{tabular}{|c|c|c|c|}
\hline & $\begin{array}{c}\text { OSCC with Lymph node } \\
\text { metastasis }(n=41)\end{array}$ & $\begin{array}{l}\text { OSCC Without Lymph } \\
\text { node metastasis }(n=45)\end{array}$ & P Value \\
\hline \multicolumn{4}{|l|}{ 1. Age } \\
\hline$\leq 50$ & 16 & 18 & \multirow{2}{*}{1.000} \\
\hline$>50$ & 25 & 27 & \\
\hline \multicolumn{4}{|l|}{$2 . \operatorname{Sex}$} \\
\hline Male & 29 & 28 & \multirow{2}{*}{0.495} \\
\hline Female & 12 & 17 & \\
\hline \multicolumn{4}{|l|}{ 3. Grading of OSCC } \\
\hline WDSCC & 24 & 27 & \multirow{3}{*}{0.703} \\
\hline MDSCC & 09 & 12 & \\
\hline PDSCC & 08 & 06 & \\
\hline \multicolumn{4}{|l|}{ 4. Site } \\
\hline Buccal mucosa & 17 & 23 & \multirow{7}{*}{0.298} \\
\hline Dorsum of tongue & 02 & 01 & \\
\hline Floor of mouth & 03 & 01 & \\
\hline Gingivo buccal sulcus & 04 & 05 & \\
\hline Lateral border of tongue & 12 & 06 & \\
\hline Reteromolar trigone & 02 & 05 & \\
\hline Lower lip & 01 & 04 & \\
\hline
\end{tabular}

In Patients without lymph node metastases, 18 were in age groups of $\leq 50$ years and 27 cases were $>50$ years of age. whereas patients with lymph node metastases, 16 were in the age group of $\leq 50$ years and 25 were $>50$ years of age. In the present study, there were no statistically significant association between OSCC with and without lymph node metastases and clinical variables like age, sex, site, and histological differentiation (Table 6).

\section{Discussion}

Amongst the 86 cases of oral squamous cell carcinoma, maximum numbers of patients were in the age of 51-60 years $(36.05 \%)$ with mean age of $53.733 \pm 11.719$ years which is consistent with studies conducted by Dhar PK et al., [12] Mehrotra R et al,[13] Khandekar SP et al, [14] Mishra V et al.[15]. In the present study, it was observed that out of 86 cases of OSCC, majority i.e. 57 were male and 29 were female. Studies conducted by Durazzo MD et al,[16] Khandekar et al [14] Dias et al [17] Brandizzi et al [18] Kruse AL et al [19] also found a male preponderance.

The fact that oral cancer affects men more than women may be observed in all of the studies conducted in India as well as other countries. However, gender is not a risk factor per se in oral malignancies. The difference may be due to the high rate of tobacco and alcohol consumption among males. Tobacco addiction among males includes both chewing and smoking. In our society females usually do not indulge in smoking although a disturbing rising trend is noted. Most of the studies found that the maximum incidence of oral malignancies in people was over 50-60 years of age. Hence, screening programs targeting men over 50 years, would help in early diagnosis of oral malignancy and therefore likely to improve the treatment outcome.
Most of the cases were well differentiated OSCC (59.30\%). Broder's grading system was used for grading of tumor. Well differentiated squamous cell carcinomas $(n=51)$ showed sheets and nests of tumor cells with large hyperchromatic nuclei. The presence of individual cell keratinisation with keratin pearl formation was consistently seen in almost all the cases and is the prominent features of well differentiated SCC. Intercellular bridges, atypical mitoses and stromal lymphoplasmacytic infiltrate are seen in many cases. The pattern of invasion was predominantly pushing and bands type in most of the cases.

Moderately differentiated squamous cell carcinomas $(n=21)$ showed nuclear pleomorphism with decrease in individual cell keratinization. The pattern of invasion was predominantly in bands, cords and islands with minority of cases showing pushing pattern of invasion. Poorly differentiated squamous cell carcinomas $(n=14)$ showed predominantly immature cells with numerous atypical mitoses with absence of individual cell keratinisation. The tumor cells showed lack of cohesiveness. The pattern of invasion was seen predominantly in single cells, cords and islands. In a study conducted by Iype EM et al. in 2001, [20] they found $52.6 \%$ well-differentiated tumors, $34.2 \%$ moderately differentiated and $4.2 \%$ poorly differentiated 
tumors. For $8.9 \%$ patients, the degree of differentiation was not recorded. Ahluwalia et al [21]. found $65.97 \%$ well differentiated, $24.49 \%$ moderately differentiated, and $9.53 \%$ poorly differentiated OSCC. Patel MM et al [22] found $60.12 \%$ well differentiated, $38.7 \%$ moderately differentiated, and $1.18 \%$ poorly differentiated OSCC. Dragomir LP et al. [23] showed 52.9\% well differentiated, $35.3 \%$ moderately differentiated, and $11.8 \%$ poorly differentiated OSCC.

Epithelial E cadherin expression decreases from well differentiated carcinoma to poorly differentiated carcinoma. Differences in the E-cadherin expression between the histopathological grades were found to be statistically significant $(\mathrm{P}<0.001)$. In a study conducted by Kaur G et al. [24]; Expression of E-cadherin in normal oral epithelium, primary OSCC $(\mathrm{n}=37)$ and metastatic lymph nodes $(\mathrm{n}=10)$ were analyzed by immunohistochemistry. An inverse correlation was observed between epithelial Ecadherin immunoreactivity and degree of tumour differentiation. In advanced cases of OSCC, expression of E-cadherin was found to be significantly reduced. But, an increased E-cadherin expression was recorded in early lesions, that is, in well differentiated $(\mathrm{n}=9)$ and moderately differentiated OSCC $(n=13)$. Moreover, in majority of metastatic lymph node, E-cadherin was negative (7/10). Nijkamp MM et al. [25] found that, compared to tumors with high expression of E-cadherin, tumours with reduced expression showed a significantly higher incidence of metastasis $(19 \%$ versus $81 \%, \mathrm{p}=0.004)$. Zaid $\mathrm{KW}$ et al., [26] found a decrease in E-cadherin expression with histological grades of OSCC.

Afrem MC et al. [27] observed a decrease E-cadherin reactivity in parallel with decreasing tumor differentiation and with the increase of invasion pattern of tongue carcinoma. Akhtar K et al [28] observed a significantly reduced expression of E-cadherin expression in invasive oral squamous cell carcinomas compared to dysplasia and carcinoma in situ. Whereas, in a study conducted by Chaw SY et al. [29] they observed a decrease in E-cadherin expression when comparing normal epithelium to mild dysplasia and to moderate-severe dysplasia while a small increase in E-cadherin expression was noted from moderate-severe dysplasia to OSCC tissues however, differences in E-cadherin expression were not significant between the histopathological grades.

Any significant difference in E- cadherin expression in OSCC with and without lymph node metastases was not observed. Various studies showed a significant association between decrease or loss of expression of E Cadherin and lymph node metastases. [30-33] However, few others failed to prove the same [34-37]. The present study is consistent with these studies. A number of factors associated with the methodology including method of evaluation of immunostaining may be the reason for the inconsistency of the results. There are also some limitations to this study like lower number of cases, lack of clinical staging and postoperative follow-up data of the selected cases. Also, the study was conducted over the cases that came to Silchar medical college which may not represent the entire population of that region.

\section{Conclusion}

The present study shows that epithelial E cadherin expression decreases from well differentiated carcinoma to poorly differentiated carcinoma in OSCC. Various studies showed a significant association between decrease or loss of expression of E Cadherin and lymph node metastases Although the present study failed to prove this, further research on E-cadherin and other related biomolecules can help us in early diagnosis and treatment of oral squamous cell carcinoma as well as predicting the tumor behavior.

\section{What the study adds to the existing knowledge?}

It was observed that decrease E-cadherin expression in oral squamous cell carcinomas, but it may not be the only key factor for regional lymph node metastases. The role other adhesion molecules and various related proteases such as MMP (matrix metalloproteinase), cathepsin D, plasminogen activator which helps in invasion of extracellular matrix needs to be studied further for occurrence of regional lymph node metastasis.

\section{Author's contribution}

This research work was done by Dr. Anirban Goswami under the guidance of Dr. Leena Talukdar.

Funding: No funding sources

Conflict of interest: None declared

Ethical Approval: This study was approved by the Institutional Ethics Committee

Acknowledgements: Authors acknowledge the support of the technical staff of the pathology lab and the departmental head Dr (Prof.) R.N. Chaubey and Dr.(Prof.) D. Datta.

\section{References}

1. Brinkman BM, Wong DT. Disease mechanism and biomarkers of oral squamous cell carcinoma. Curr Opin Oncol. 2006;18(3):228-233. doi: 10.1097/01.cco.0000 219250. 15041.f8.

2. Krolls SO, Hoffman S. Squamous cell carcinoma of the oral soft tissues: a statistical analysis of 14,253 cases by age, sex, and race of patients. J Am Dent Assoc. 1976; 92 (3): 571-574. doi: 10.14219/jada.archive. 1976. 0556. 
3. Scully C. Oral cancer aetiopathogenesis; past, present and future aspects. Med Oral Patol Oral Cir Bucal. 2011;16(3):e306-e311. doi: 10.4317/medoral.16.e306.

4. Epstein JB, Zhang L, Rosin M. Advances in the diagnosis of oral premalignant and malignant lesions. J Can Dent Assoc. 2002;68(10):617-621.

5. Glazer CA, Chang SS, Ha PK, Califano JA. Applying the molecular biology and epigenetics of head and neck cancer in everyday clinical practice. Oral Oncol. 2009;45(4-5): 440-446. doi: 10.1016/j.oraloncology.2008.05.013. Epub 2008 Jul 31.

6. Molinolo AA, Amornphimoltham $\mathrm{P}$, Squarize $\mathrm{CH}$, Castilho RM, Patel V, Gutkind JS. Dysregulated molecular networks in head and neck carcinogenesis. Oral Oncol. 2009;45(4-5):324-334. doi: 10.1016/j.oraloncology.2008. 07. 011. Epub 2008 Sep 19.

7. Liu LK, Jiang XY, Zhou XX, Wang DM, Song XL, Jiang HB. Upregulation of vimentin and aberrant expression of Ecadherin/beta-catenin complex in oral squamous cell carcinomas: correlation with the clinicopathological features and patient outcome. Mod Pathol. 2010;23(2):213224. doi: 10.1038/ modpathol.2009.160. Epub 2009 Nov 13.

8. Pannone G, Santoro A, Feola A, Bufo P, Papagerakis P, Lo Muzio L, et al. The role of E-cadherin down-regulation in oral cancer: $\mathrm{CDH} 1$ gene expression and epigenetic blockage. Curr Cancer Drug Targets. 2014;14(2):115-127. doi: 10.2174/1568009613666131126115012.

9. Bringuier PP, Umbas R, Schaafsma HE, Karthaus HF, Debruyne FM, Schalken JA. Decreased E-cadherin immunoreactivity correlates with poor survival in patients with bladder tumors. Cancer Res. 1993;53(14):3241-3245.

10. Deng QW, He BS, Pan YQ, Sun HL, Xu YQ, Gao TY, et al. Roles of E-cadherin (CDH1) genetic variations in cancer risk: a meta-analysis. Asian Pac J Cancer Prev. 2014; 15(8):3705-3713. doi: 10.7314/apjcp.2014.15.8.3705.

11. Taşkin S, Dünder I, Erol E, Taşkin EA, Kiremitçi S, Öztuna D, et al. Roles of E-cadherin and cyclooxygenase enzymes in predicting different survival patterns of optimally cytoreduced serous ovarian cancer patients. Asian Pac J Cancer Prev. 2012;13(11):5715-5719.

12. Dhar PK, Rao TR, Sreekumaran Nair N, Mohan S, Chandra S, Bhat KR, Rao K. Identification of risk factors for specific subsites within the oral and oropharyngeal region--a study of 647 cancer patients. Indian J Cancer. 2000;37(2-3):114-122.

13. Mehrotra R, Singh M, Kumar D, Pandey AN, Gupta RK, Sinha US. Age specific incidence rate and pathological spectrum of oral cancer in Allahabad. Indian J Med Sci. 2003;57(9):400-404.
14. Khandekar SP, Bagdey PS, Tiwari RR. Oral cancer and some epidemiological factors: A hospital-based study. Indian J Community Med. 2006;31(3):157-159.

15. Misra V, Singh PA, Lal N, Agarwal P, Singh M. Changing pattern of oral cavity lesions and personal habits over a decade: Hospital based record analysis from Allahabad. Indian J Community Medi: Indian Assoc Prevent Social Med. 2009;34(4):321-325. doi: 10.4103/ 0970-0218.58391.

16. Durazzo MD, Araujo CE, Neto B, de Souza J, Potenza AD, Costa P, Takeda F, et al. Clinical and epidemiological features of oral cancer in a medical school teaching hospital from 1994 to 2002: increasing incidence in women, predominance of advanced local disease, and low incidence of neck metastases. Clinics. 2005;60(4):293-298. doi: http:// dx.doi.org/10.1590/S1807-59322005000400006.

17. Dias GS, Almeida AP. A histological and clinical study on oral cancer: descriptive analyses of 365 cases. Med Oral Patol Oral Cir Bucal. 2007;12(7):E474-E478.

18. Brandizzi D, Gandolfo M, Velazco ML, Cabrini RL, Lanfranchi HE. Clinical features and evolution of oral cancer: A study of 274 cases in Buenos Aires, Argentina. Med Oral Patol Oral Cir Bucal. 2008;13(9):E544-E548.

19. Kruse AL, Bredell M, Grätz KW. Oral squamous cell carcinoma in non-smoking and non-drinking patients. Head Neck Oncol. 2010;2:24. doi: 10.1186/1758-3284-2-24.

20. Iype EM, Pandey M, Mathew A, Thomas G, Sebastian $\mathrm{P}$, Nair MK. Oral cancer among patients under the age of 35 years. J Postgrad Med. 2001;47(3):171-176.

21. Ahluwalia H, Gupta SC, Singh M, Gupta SC, Mishra V, Singh PA, et al. Spectrum of Head-Neck cancers at Allahabad. Indian J Otolaryngol Head Neck Surg. 2001;53 (1): 16-21. doi: 10.1007/BF02910972.

22. Patel MM, Pandya AN. Relationship of oral cancer with age, sex, site distribution and habits. Indian $\mathrm{J}$ Pathol Microbiol. 2004;47(2):195-197.

23. Dragomir LP, Simionescu C, Mărgăritescu C, Stepan A, Dragomir IM, Popescu MR. P53, p16 and Ki67 immunoexpression in oral squamous carcinomas. Rom $\mathrm{J}$ Morphol Embryol. 2012;53(1):89-93.

24. Kaur G, Carnelio S, Rao N, Rao L. Expression of Ecadherin in primary oral squamous cell carcinoma and metastatic lymph nodes: an immunohistochemical study. Indian J Dent Res. 2009;20(1):71-76.

25. Nijkamp MM, Span PN, Hoogsteen IJ, van der Kogel AJ, Kaanders JH, Bussink J. Expression of E-cadherin and vimentin correlates with metastasis formation in head and neck squamous cell carcinoma patients. Radiother Oncol. 2011;99(3):344-348. doi: 10.1016/j.radonc.2011.05.066. Epub 2011 Jun 22.

Pathology Update: Tropical Journal of Pathology \& Microbiology Available online at: www.medresearch.in 890 | P a g e 
26. Zaid $\mathrm{KW}$. Immunohistochemical assessment of Ecadherin and $\beta$-catenin in the histological differentiations of oral squamous cell carcinoma. Asian Pac J Cancer Prev. 2014;15(20):8847-8853. doi: 10.7314/apjcp.2014.15.20. 8847.

27. Afrem MC, Mărgăritescu C, Crăiţoiu MM, Ciucă M, Şarlă CG, Cotoi OS. The immunohistochemical investigations of cadherin "switch" during epithelialmesenchymal transition of tongue squamous cell carcinoma. Rom J Morphol Embryol. 2014; 55(3): 10491056 .

28. Akhtar K, Ara A, Siddiqui SA, Sherwani RK. Diagnostic and prognostic significance of E-cadherin and vimentin in oral cancer metastasis. Ann Pathol Lab Med. 2016; 3(1): A1-A8.

29. Chaw SY, Abdul Majeed A, Dalley AJ, Chan A, Stein S, Farah CS. Epithelial to mesenchymal transition (EMT) biomarkers--E-cadherin, beta-catenin, APC and Vimentin-in oral squamous cell carcinogenesis and transformation. Oral Oncol. 2012;48(10):997-1006. doi: 10.1016/j. oraloncology. 2012.05.011. Epub 2012 Jun 14.

30. Laxmidevi LB, Angadi PV, Pillai RK, Chandreshekar C. Aberrant $\beta$-catenin expression in the histologic differentiation of oral squamous cell carcinoma and verrucous carcinoma: an immunohistochemical study. Journal of oral science. 2010;52(4):633-640. doi: https:// doi.org/10.2334/josnusd.52.633.

31. Diniz-Freitas M, García-Caballero T, Antúnez-López J, Gándara-Rey JM, García-García A. Reduced E-cadherin expression is an indicator of unfavourable prognosis in oral squamous cell carcinoma. Oral Oncol. 2006;42(2):190-200. Epub 2005 Oct 24. doi: 10.1016/j.oraloncology.2005. 07.010
32. Cruz MC, Pereira AL, Lopes FF, Nonaka CF, Silva RR, Freitas Rde A, et al. Immunohistochemical expression of Ecadherin and CD44v6 in squamous cell carcinomas of the lower lip and tongue. Braz Dent J. 2009;20(1):64-69. doi: http://dx.doi.org/10.1590/S0103-64402009000100011.

33. Andrews NA, Jones AS, Helliwell TR, Kinsella AR. Expression of the E-cadherin-catenin cell adhesion complex in primary squamous cell carcinomas of the head and neck and their nodal metastases. $\mathrm{Br} \mathrm{J}$ Cancer. 1997;75(10):1474-1480. doi: 10.1038/bjc.1997.252.

34. Kurtz KA, Hoffman HT, Zimmerman MB, Robinson RA. Decreased E-cadherin but not $\beta$-catenin expression is associated with vascular invasion and decreased survival in head and neck squamous carcinomas. OtolaryngologyHead and Neck Surgery. 2006;134(1):142-146.

35. Gurkiran K, Sunitha C, Nirmala R, Laxmi R: Expression of E-cadherin in primary oral squamous cell carcinoma and metastatic lymph nodes: An immunohistochemical study. Indian J Dent Res. 2009;20 (1):71-76.

36. Wang X, Zhang J, Fan M, Zhou Q, Deng H, Aisharif $\mathrm{MJ}$, The expression of E-cadherin at the invasive tumor front of oral squamous cell carcinoma: immunohistochemical and RT-PCR analysis with clinicopathological correlation. Oral Surg Oral Med Oral Pathol Oral Radiol Endod. 2009;107(4):547-554. doi: 10.1016/j.tripleo. 2008. 11.021 .

37. Rodrigo JP, Domínguez F, Alvarez C, Manrique C, Herrero A, Suárez C. Expression of E-cadherin in squamous cell carcinomas of the supraglottic larynx with correlations to clinicopathological features. Eur J Cancer. 2002; 38(8): 1059-1064. doi: 10.1016/s0959-8049(01) 00399- 9 .

\section{How to cite this article?}

Talukdar L, Goswami A. An immunohistochemical study of e-cadherin expression in primary oral squamous cell carcinoma and metastatic lymph node in a tertiary care centre. Trop J Path Micro 2019;5(11):884-891.doi:10.17511/jopm.2019.i11.09 